RESEARCH ETHICS

\title{
The standard of care debate: the Declaration of Helsinki versus the international consensus opinion
}

\author{
R K Lie, E Emanuel, C Grady, D Wendler
}

J Med Ethics 2004;30:190-193. doi: 10.1136/jme.2003.006031

The World Medical Association's revised Declaration of Helsinki endorses the view that all trial participants in every country are entitled to the worldwide best standard of care. In this paper the authors show that this requirement has been rejected by every national and international committee that has examined this issue. They argue that the consensus view now holds that it is ethically permissible, in some circumstances, to provide research participants less than the worldwide best care. Finally, the authors show that there is also consensus regarding the broad conditions under which this is acceptable.

See end of article for authors' affiliations

Correspondence to: Professor R Lie, Department of Public Health and Primary Health Care, Kalfarveien 31 , University of Bergen, Bergen, Norway; Reidar.Lie@fil.uib.no

Received

26 July 2003

Revised version received 11 September 2003

Accepted for publication

21 October 2003
P erhaps the most contentious debate in research ethics during the past few years has been over what standard of care is owed to participants in clinical trials in developing countries. $^{1-5}$ In 2000, the World Medical Association (WMA) revised the Declaration of Helsinki, seemingly endorsing the view that all trial participants in every country are entitled to the worldwide best standard of care. Many perceived this announcement to settle the matter and define the ethically acceptable position. Paradoxically, the Declaration of Helsinki requirement has been rejected by every national and international committee that has examined this issue from Europe to the United States and beyond. ${ }^{6-10}$ Indeed, what we believe is the consensus view now holds that it is ethically permissible, in some circumstances, to provide research participants less than the worldwide best care. This should be the worldwide ethical standard.

\section{DECLARATION OF HELSINKI'S REQUIREMENT}

The principal support for the claim that research participants in developing countries must be provided the worldwide best care comes from the 1996 version of the Declaration of Helsinki: "in any medical study, every patient-including those of a control group, if any-should be assured of the best proven diagnostic and therapeutic method". After contentious debate, the WMA upheld this position at its 2000 Edinburgh meeting, adopting essentially the same principle, with the minor modification of changing "best proven method" to "best current method." Importantly, not only does this position require that research participants in control groups in randomised trials receive the world- wide best care, but that all participants in all research studies in developing countries receive the best available diagnostic tests. In addition, it precludes early phase testing of drugs or interventions that might be an improvement over existing treatment in the host country if they are likely to be less beneficial than the available treatment in developed countries.

In response to criticism that this requirement would prohibit a placebo control group in trials of trivial conditions when there is an established effective treatment, such as rhinorhea or alopecia, the WMA issued a clarification that allowed such trials. The clarification would allow placebo controls if the trial participants are not subject to serious or irreversible harm. What has confused many is that the clarification apparently also allows placebo control trials in any situation where there is a "compelling and scientifically sound methodological reason" for their use. As far as we know nobody - not even strong defenders of placebo controlled trials such as Robert Temple and Susan Ellenberg-has argued that a "compelling and scientifically sound methodological reason" should be the only condition; there has to be some additional condition, such as the first point in the clarification requiring that trial participants are not subject to serious or irreversible harm. ${ }^{11}{ }^{12}$ The fact that the WMA apparently has not noticed, nor attempted to correct, this obvious problem with the clarification, further strengthens our claim that the Declaration of Helsinki has lost its moral authority with regard to this controversy in research ethics. We conclude that it is not at all clear what relevance the clarification has, if any, to the issue of allowing a different level of care for research in developing countries.

The Declaration of Helsinki's position has been defended on several grounds. ${ }^{13}$ Firstly, some have argued that it is always possible to test interventions that may benefit developing countries against the best proven treatment; all that is required is methodological ingenuity, not ethical compromise. ${ }^{3}$ Others argue that even if obtaining useful data for developing countries sometimes requires that research participants receive less than the worldwide best care, it is nonetheless unethical to do so. Such trials violate researchers' obligations to their patients, and create an

Abbreviations: CIOMS, Council for International Organizations of Medical Sciences; NBAC, National Bioethics Advisory Commission; UNAIDS, United Nations Programme on HIV/AIDS; WMA, World Medical Association 
insidious double standard that accepts for the poor what it rejects as unethical for the rich. ${ }^{13}$ The decision by the WMA to uphold the requirement for a universal standard of care in clinical trials seemed based mostly on the latter concern. Because many people regard the Declaration of Helsinki as the final word regarding research ethics, the requirement may come to be viewed as definitive by the research community. It has gone largely unnoticed that the Declaration of Helsinki in fact turns out to be the minority opinion.

\section{THE INTERNATIONAL CONSENSUS OPINION}

In the midst of all the controversy, a wide range of public and private, national and international groups critically examined the so called standard of care debate, and issued their own evaluations (see table 1). Remarkably, every one of these evaluations disagrees with the Declaration of Helsinki on this issue. They all affirm that, under certain conditions, it is ethically justifiable to conduct a trial in a developing country in which the participants are provided medical interventions that are less than the worldwide best standard of care. Even more remarkably, these groups all delineate essentially the same three conditions on ethically acceptable exceptions to providing research participants the worldwide best standard of care. These three conditions are:

- Valid science: there must be a valid scientific reason for using a lower standard of care than that available elsewhere:

- Social benefits: the research must provide a sufficient level of benefit for the host community, and

- Favourable individual risk:benefit ratio: there must be an acceptable balance of risks and potential benefits for the individual participants in the trial.

With the exception of the Declaration of Helsinki, these three conditions represent a broad consensus on the permissibility of exceptions to the general rule requiring that all research participants receive the best standard of care. Not surprisingly, however, the various commissions and bodies specify or interpret these conditions in different ways. Identifying the specific areas of disagreement should facilitate deliberation on them, with the goal of attaining even broader consensus on this vital issue.

\section{VALID SCIENTIFIC REASONS}

The recent revision of the Council for International Organizations of Medical Sciences (CIOMS) guidelines provides the clearest statement of the need for a scientifically valid reason for using a lower standard of care.

The scientific and ethical review committee must be satisfied that the established effective intervention cannot be used as comparator because its use would not yield scientifically reliable results that would be relevant to the health needs of the study population. ${ }^{6}$

The other groups that have looked at this issue accept essentially the same condition, although usually with less specificity. For instance, the National Bioethics Advisory Commission (NBAC) demands that an ethics committee should review the "justification for using an alternative design." ${ }^{8}$

The valid science condition can be interpreted in various ways. CIOMS endorses perhaps the most stringent interpretation, requiring that use of the best proven treatment in the control group would not yield any scientifically reliable results. A weaker requirement might be that use of the best proven treatment in the control group would be so costly or logistically difficult, given the limited resources in the host community, as to make it extremely difficult, although not impossible, to get reliable results. Most of the guidelines adopt this less strict interpretation. For instance, the Nuffield Council requires that researchers use "the most appropriate research design", specifying that considerations of practical feasibility are relevant to assessing when it is acceptable to provide research participants less than the best standard of care. ${ }^{9}$

\begin{tabular}{|c|c|c|c|}
\hline Organisation & Valid science & Social benefits to host country & $\begin{array}{l}\text { Favourable individual } \\
\text { risk:benefit ratio }\end{array}$ \\
\hline UNAIDS $^{10}$ & $\begin{array}{l}\text { The research protocol should } \\
\text { be scientifically appropriate }\end{array}$ & $\begin{array}{l}\text { Plans should start during initial } \\
\text { stages of vaccine } \\
\text { development to ensure } \\
\text { availability }\end{array}$ & $\begin{array}{l}\text { The minimum should be to } \\
\text { provide the highest level of } \\
\text { care attainable in the host } \\
\text { country }\end{array}$ \\
\hline $\mathrm{NBAC}^{8}$ & $\begin{array}{l}\text { There needs to be a justification } \\
\text { for the alternative trial design }\end{array}$ & $\begin{array}{l}\text { An explanation of how } \\
\text { interventions proven to be } \\
\text { effective from the research will } \\
\text { become available to the host } \\
\text { country population }\end{array}$ & $\begin{array}{l}\text { Ethics committee needs to } \\
\text { assess the risks to the } \\
\text { participants }\end{array}$ \\
\hline $\mathrm{ClOMS}^{6}$ & $\begin{array}{l}\text { Established effective } \\
\text { intervention would not yield } \\
\text { scientifically reliable results }\end{array}$ & $\begin{array}{l}\text { Trial should be responsive to } \\
\text { the health needs of the trial } \\
\text { population and there should } \\
\text { be assurance of reasonable } \\
\text { availability }\end{array}$ & $\begin{array}{l}\text { Potential risks and benefits } \\
\text { are reasonably balanced } \\
\text { and risks are minimised }\end{array}$ \\
\hline $\mathrm{EGE}^{7}$ & $\begin{array}{l}\text { Research methods are } \\
\text { necessary to the aims pursued } \\
\text { and that no alternative more } \\
\text { acceptable methods are } \\
\text { available }\end{array}$ & $\begin{array}{l}\text { Justification may be to simplify } \\
\text { or reduce costs of treatment for } \\
\text { host country }\end{array}$ & $\begin{array}{l}\text { Special attention should be } \\
\text { paid to the risk/benefit ratio } \\
\text { at the individual level }\end{array}$ \\
\hline Nuffield Council & $\begin{array}{l}\text { There must be an appropriate } \\
\text { research design to answer the } \\
\text { research question }\end{array}$ & $\begin{array}{l}\text { Sustainability and affordability } \\
\text { of the standard of care used } \\
\text { need to be considered }\end{array}$ & $\begin{array}{l}\text { Minimum should be the } \\
\text { standard of care country } \\
\text { endeavours to provide } \\
\text { nationally }\end{array}$ \\
\hline
\end{tabular}




\section{SOCIAL BENEFITS TO THE HOST COMMUNITY}

All the guidelines that dissent from the Declaration of Helsinki prohibition on research using less than the worldwide best standard of care require that the purpose of the research must be to develop interventions that can be implemented in the host community, and thereby provide social benefit for it. Most clearly, the European Group on Ethics allows for exceptions to the requirement of using the worldwide best standard only when ${ }^{6}$ "...the primary goal of the clinical trial is to try to simplify or to decrease the costs of treatment for countries where the standard of treatment is not available for logistic reasons or inaccessible because of costs".7.

Again, CIOMS adopts the strictest interpretation of this social benefit condition. Not only does it demand that the purpose of the trial is to identify a more affordable or logistically simpler treatment for the host community, but that the "purpose of the study is to make available to the population of the country or community an effective alternative to an established effective intervention that is locally unavailable." ${ }^{\prime 6}$ Thus, CIOMS seems to require not merely the possible usefulness or relevance of the intervention, but a concrete plan at the start of these trials that ensures the intervention will be provided if the research trial proves the treatment safe and effective.

\section{FAVOURABLE INDIVIDUAL RISK:BENEFIT RATIO}

The third condition requires an acceptable risk:benefit ratio for individual research participants from developing countries. Practically, this means that the participants should not be denied any treatments with significant benefits that they would ordinarily receive. In this sense, research participants should be no worse off than they would be if they did not participate in the trial. For instance, the Nuffield Council requires, as part of the trial, provision of those treatments the community endeavours to provide nationally-even if the community actually fails to fulfil its own standards. ${ }^{9}$ The guidance document from United Nations Programme on HIV/ AIDS (UNAIDS) goes further, requiring that the minimal medical care should be the highest level of care attainable in the host community. ${ }^{10}$

\section{ADJUDICATING BETWEEN THE DECLARATION OF HELSINKI AND THE CONSENSUS PERSPECTIVE}

How should the disagreement between the ban advocated by the Declaration of Helsinki and the allowance of exceptions by other national and international guidelines be adjudicated? Clearly, moral questions are not decided simply by which view gets the most votes. It is also patently obvious that there is presently no worldwide consensus opinion on this issue, as a number of groups, organisations, and individuals have voiced strong support for the position affirmed by the 2000 Declaration of Helsinki. Nevertheless, there are important reasons why what we have labelled the "consensus position" is more justifiable, or at least should be recognised as an ethically valid approach.

Firstly, the guidelines advocating the consensus opinion have been the product of widespread consultation and involvement by clinical researchers, bioethicists, and individuals with research experience in developing countries. In addition, in several cases, there were consultations conducted in developing countries themselves-for example, before the UNAIDS document was adopted, consultative meetings were carried out in Africa, Latin America, and Asia. ${ }^{14}$ The Nuffield Council document included representatives from Africa and Asia in its working group, consulted with additional representatives from developing countries, and conducted one of its meetings in Chennai, India. ${ }^{9}$ The CIOMS process included several meetings with a wide representation from all continents. Finally, it is interesting to note that a similar position was adopted independently in the context of another trial, organised for and by South African researchers without external sponsorship to address the issue of perinatal transmission. ${ }^{15}$

Secondly, the Declaration of Helsinki provides declarative pronouncements devoid of justification or elaboration. The other guidelines provide justifications and elaborations for their positions. Between commands and reasoned arguments, the latter always has ethical priority. Thirdly, the three conditions on allowable exceptions were arrived at independently by numerous groups, and are intended to ensure that a lower standard of care is used only when it has the potential to improve medical care for the world's poor.

Finally, ethical guidelines should prohibit behaviours and practices that are clearly and incontrovertibly unethical, while recognising that there may be more than one ethically acceptable approach to a difficult issue. The fact that many commissions, councils, and other groups, without obvious conflicts of interest or biases, came to the same view, suggests that even if the position is not the optimal ethical standard, it is at least not clearly unethical. This suggests that research following these guidelines should be ethically permitted.

\section{CONCLUSION}

Many people believe that the Declaration of Helsinki's prohibition of clinical research studies in developing countries that do not provide the worldwide best standard of care established the definitive ethical standard. Ironically, every other commission and body that has considered this difficult issue has rejected the Declaration of Helsinki's pronouncement. More importantly, these other bodies have all agreed on essentially the same three concrete conditions-valid science, social benefit, and favourable risk:benefit ratio for participants-that must be fulfilled to grant an exception. This broad consensus has two important implications. Firstly, review bodies should permit research that provides less than the worldwide best standard of care if it adheres to any of the major versions of the three conditions, including those from the Nuffield Council, NBAC, or CIOMS. Secondly, the debate over whether we can allow such research should shift focus; those who continue to want to advocate a universal standard of care now have an obligation to state clearly why they believe research that fulfils these three conditions is unethical. More importantly, we believe that energy should now be directed to resolving the remaining areas of disagreement regarding how to specify the conditions under which it can occur.

\section{Authors' affiliations}

R K Lie, Department of Public Health and Primary Health Care, University of Bergen, Bergen, Norway R K Lie, E Emanuel, C Grady, D Wendler, Department of Clinical Bioethics, National Institutes of Health, Bethesda, MD, USA

The opinions expressed are the authors' own. They do not reflect any position or policy of the National Institutes of Health, Public Health Service, or Department of Health and Human Services.

\section{REFERENCES}

1 Angell $M$. The ethics of clinical research in the third world. N Engl J Med 1997:337:847-9.

2 Annas GJ, Grodin MA. Human rights and maternal-fetal HIV transmission trials in Africa. Am J Public Health 1998;88:560-3.

3 Lurie $\mathbf{P}$, Wolf SM. Unethical trials of interventions to reduce perinatal transmission of the human immunodeficiency virus in developing countries. N Engl J Med 1997;337:853-5.

4 Schüklenk U, Ashcroft R. International research ethics. Bioethics 2000;14:158-72.

5 Varmus $\mathrm{H}$, Satcher D. Ethical complexities of conducting research in developing countries. N Engl J Med 1997;337:1003-5. 
6 Council for International Organizations of Medical Sciences. International ethical guidelines for biomedical research involving human subjects. Geneva: CIOMS, 2002.

7 European Group on Ethics in Science and New Technologies. Ethical aspects of clinical research in developing countries. Brussels: European Commission, 2003.

8 National Bioethics Advisory Commission. Ethical and policy issues in international research: Clinical trials in developing countries. Vol I. Bethesda, MD: National Bioethics Advisory Commission, 2001.

9 Nuffield Council on Bioethics. The ethics of research related to research in developing countries. London: Nuffield Council on Bioethics, 2002.

10 Joint United Nations Program on HIV/AIDS. Ethical considerations in HIV preventive vaccine research. UNAIDS guidance document. Geneva: UNAIDS, 2000.
11 Ellenberg SS, Temple R. Placebo-controlled trials and active control trials in the evaluation of new treatments. Part 2. Practical issues and specific cases. Ann Intern Med 2000;133:464-70.

12 Temple R, Ellenberg SS. Placebo-controlled trials and active control trials in the evaluation of new treatments. Part 1: Ethical and scientific issues. Ann Intern Med 2000; 133:455-63.

13 Brennan TA. Proposed revisions to the Declaration of Helsinki-will they weaken the ethical principles underlying human research? N Engl J Med 2001;341:527-31.

14 Guenter D, Esparza J, Macklin R. Ethical considerations in international HIV vaccine trials: summary of a consultative process conducted by UNAIDS. J Med Ethics 2000;26:37-43.

15 Karim S. Placebo controlled trials in HIV perinatal transmission trials: A South African's viewpoint. Am J Public Health 1998;88:564-6. 